Dr Mirko Borisov, pukovnik, dipl. inž. Vojnogeografski institut, Beograd

\section{TOPOGRAFSKO-KARTOGRAFSKI SISTEM PREMA NOVIM VOJNIM STANDARDIMA}

UDC: $528.913: 355.1$

Rezime:

Rad se bavi izradom novih vojnih topografskih karata koje se od sadašnjeg topografsko-kartografskog sistema razlikuju po elementima matematičke osnove $i$ vanokvirnog sadržaja. Pri tome se posebno razmatra: elipsoid, kartografska projekcija, sistem razmere i format listova karata. Kako se postojeći geotopografski materijali mogu relativno lako prilagoditi novim standardima, dat je postupak transformacije podataka u novi referentni sistem.

Ključne reči: topografska karta, matematička osnova, transformacija.

\title{
TOPOGRAPHIC-CARTOGRAPHIC SYSTEM ACCORDING TO THE NEW MILITARY STANDARDS
}

Summary:

The article deals with producing new military topographic maps that differ from the inherited cartographic system as mathematic base and margin contents. It is treated ellipsoid, cartographic projection, scale system and format of maps. Since existent geotopographic materials can be adopted with new standard, the paper looks back on essential characteristics of transformation data to new reference system.

Key words: topographic map, mathematical base, transformation.

\section{Uvod}

Vojnogeografski institut izradio je sistem topografskih i preglednotopografskih karata, čiji se osnovni sadržaj zasniva na topografsko-fotogrametrijskom premeru zemljišta izvedenog od 1947. do 1967. godine i povremenim dopunama nakon tog vremena. Na osnovu toga, dobijen je integralni topografsko-kartografski sistem koji čine karte u razmeri 1:25000, 1:50 000, 1:100 000, 1:200 000, $1: 300000,1: 500000$ i 1:1000 000. Osnovne odlike navedenih karata zasnivaju se na istoj topografskoj i matematičkoj osnovi. One su urađene po sistemu izve- denih karata i date u konformnoj (Gaus-Krigerovoj ili Lambertovoj) kartografskoj projekciji, sa griničkim meridijanom kao početnim. Na njima su primenjena ista ili slična kartografsko-redakcijska rešenja. Drugim rečima, pomenute karte izrađene su u jedinstvenom geodetsko-kartografskom sistemu, čime je znatno olakšana njihova upotreba, koja ima posebnu namenu u vojsci.

Međutim, postojeći vojni topografsko-kartografski sistem je zastareo i ne obezbeđuje poželjnu kompatibilnost sa kartografskim sistemima savremenog sveta. To se naročito odnosi na matematičku osnovu topografskih karata koja predsta- 
vlja osnovni predmet interesovanja u ovom radu. Radi postizanja geodetsko-kartografske kompatibilnosti, odnosno prilagođavanja sadašnjeg topografsko-kartografskog sistema međunarodnim vojnim standardima i neposrednom okruženju, potrebno je primeniti nove tehničke norme (STANAG - Standardization Agreement). Zbog toga se za matematičku (geodetsku i kartografsku) osnovu topografskih karata razmatraju sledeći standardi:

- globalni elipsoid (World Geodetic System 1984 - WGS84);

- univerzalna poprečna Merkatorova projekcija (The Universal Transverse Mercator - UTM), odnosno vojna pravougla mreža UTM;

- sistem razmera (1:50 000, 1:250 000, 1:1000 000);

- format i označavanje listova.

\section{Godetska osnova}

Geodetska osnova određuje prelaz od fizičke površi Zemlje ka uslovnoj površi elipsoida, i obezbeđuje pravilan položaj topografskog sadržaja karte u odnosu na neki koordinatni sistem (mrežu) na površi elipsoida. Kada je u pitanju koordinatni sistem, on u suštini predstavlja skup uslovljenih linija i ravni koje služe kao osnova za jednoznačno određivanje položaja tačke u prostoru. Pri određivanju položaja tačaka, odnosno njihovih koordinata, najčešće se koriste pravolinijski (ortogonalni) i krivolinijski (geografski) koordinatni sistem. Oba koordinatna sistema imaju odgovarajuću svrhu i, u zavisnosti od praktičnih potreba, obavljaju se odredene transformacije iz jednog koordinatnog sistema u drugi (slika 1).

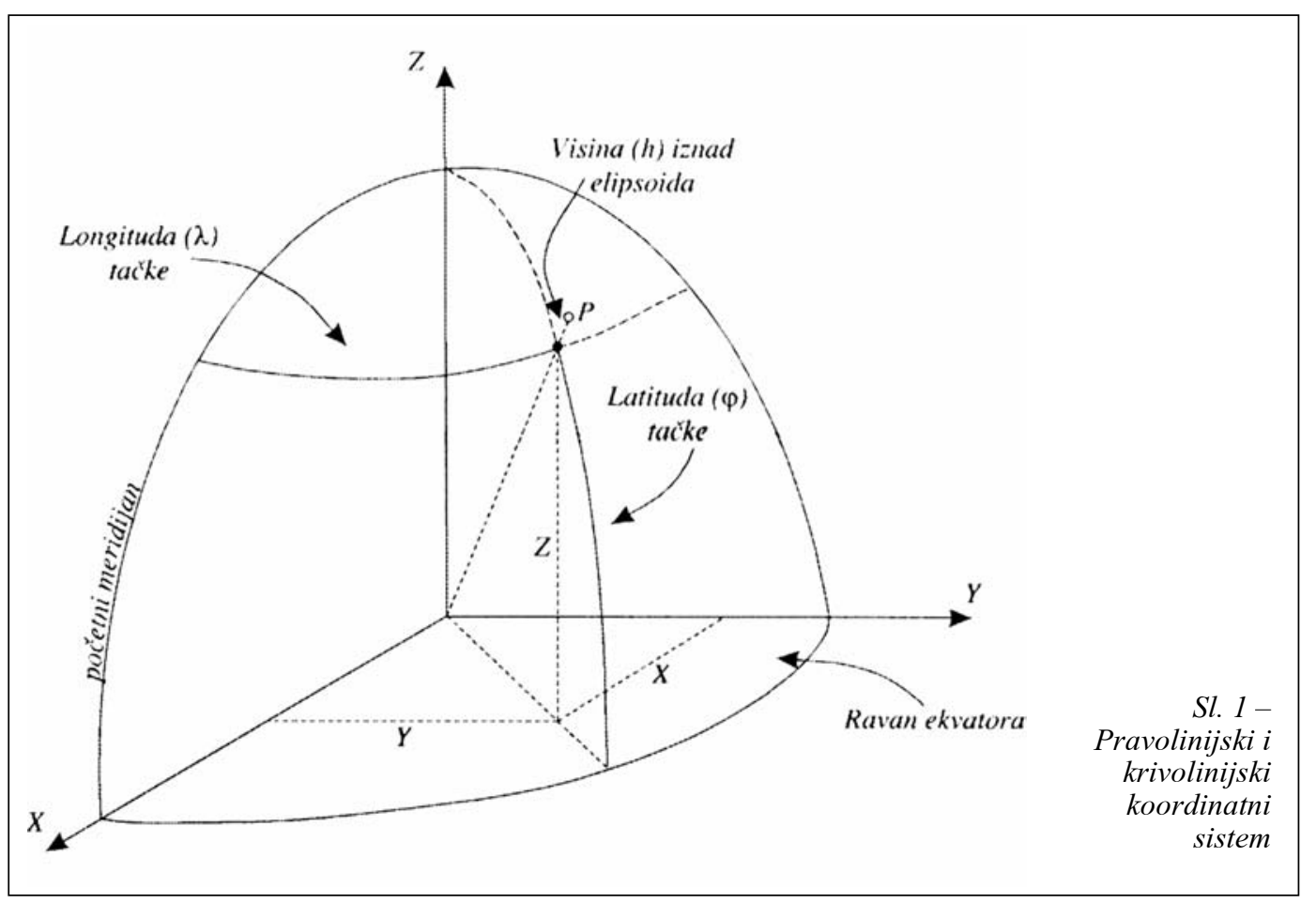


Teško je unapred zaključiti koji je oblik koordinatnog sistema pogodniji za upotrebu geoprostornih podataka, jer to, pored praktičnih razloga, zavisi i od mnogih drugih potreba. Načelno bi se moglo konstatovati da su geografski sistemi pogodniji za veće teritorije, jer geografske koordinate pripadaju jedinstvenom i univerzalnom koordinatnom sistemu za celu Zemljinu površ. Međutim, geografske koordinate su nepodesne za praktično računanje dužina i uglova, što je često potrebno. Naročito su pravougli sistemi u ravni, za razliku od geografskih, mnogo jednostavniji, jer pravougle koordinate na topografskoj karti omogućavaju neposrednu procenu dužina i međusobnih odnosa objekata u prostoru koji odgovaraju logici ljudskog razmišljanja.

Tendencija da se lokalni (Beselov) elipsoid zameni jednim globalnim elipsoidom, odnosno WGS84, koji je postao međunarodno usvojen standard za navigaciju i uopšte pozicioniranje na Zemlji, izaziva takvu potrebu i kod nas. Globalni elipsoid smešten je u telu Zemlje, tako da se (pojednostavljeno rečeno) njegova površ što bolje prilagodi površi geoida u celini, pri čemu njegov geometrijski centar koincidira sa centrom mase Zemlje, a mala osa se podudara sa obrtnom osom Zemlje. Skup svih ovih parametara za određenu vremensku epohu definiše geodetski datum.

Za prevođenje sadržaja i podataka o prostoru iz lokalnog geodetskog datuma u globalni postoji nekoliko metoda koje imaju različit nivo tačnosti i koraka transformacije između željenih geodetskih datuma. Tačnost transformacije može biti u rasponu od nekoliko centimetara do nekoliko metara, u zavisnosti od metoda i kvaliteta, te broja kontrolnih tačaka raspoloživih da definišu transformacione parametre. Metode transformacije sadašnjih izvora (nosioca) podataka mogu biti posredne ili neposredne. Posredne metode omogućavaju transformaciju geografskih koordinata $(\varphi, \lambda)$ u globalne prostorne pravougle (geocentrični ili globalni datum) koordinate, a zatim njih u odgovarajuće vrednosti lokalnih pravouglih koordinata (lokalni datum). Nakon toga se dobijene pravougle prostorne lokalne vrednosti $(x, y, z)$ transformišu u geografske koordinate. Primer za takav način jeste Helmertova sedmoparametarska metoda, koja obuhvata tri translacije $(\Delta x$, $\Delta y, \Delta z)$, tri rotacije $\left(\omega_{x}, \omega_{y}, \omega_{z}\right)$ i faktor razmere $(\mu)$, a događa se u tri koraka (WGS84 - Implementation Manual, verzija 2.2, 1995). U geometrijskom smislu to znači da lokalni model podataka o prostoru treba translirati do poklapanja koordinatnih osa, rotirati ga oko njih i promeniti mu razmeru, tako da se što više približi globalnom modelu, kao što je prikazano na slici 2.

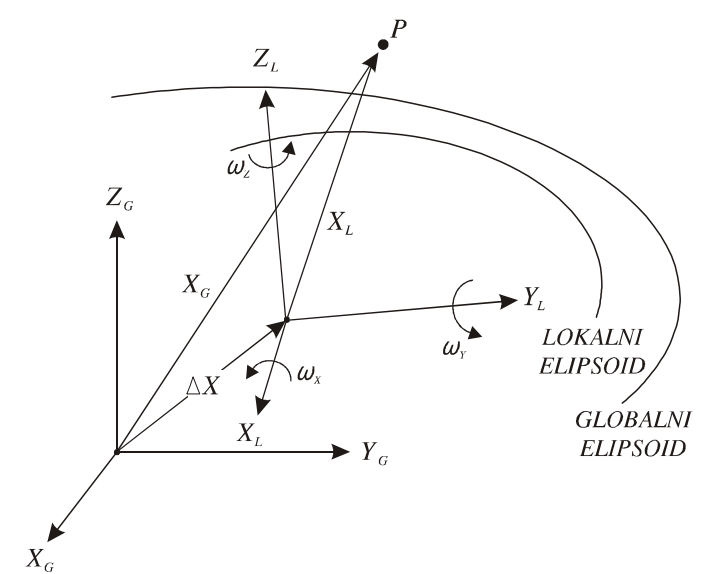

Sl. 2 - Transformacija geodetskog datuma: $X_{G}$ - položaj tačke P u globalnom sistemu, $X_{L}$ - položaj tačke u lokalnom sistemu, $\Delta X-$ parametar translacije, $\omega_{\mathrm{x}}, \omega_{\mathrm{y}}, \omega_{\mathrm{z}}-$ uglovi rotacije, $\mu$-faktor razmere 
Pored transformacije iz lokalnog $\mathrm{u}$ globalni datum na indirektan način, preko pravouglih koordinata (Helmertove formule), transformacija datuma je moguća i direktno, tj. preko krivolinijskih (geografskih) koordinata. To omogućava metoda Molodenskog, koja zahteva tri translacije $(\Delta x, \Delta y, \Delta z)$, razlike istovetnih osa $(\Delta a)$ i spljoštenosti $(\Delta f)$ za oba elipsoida (WGS84 - Implementation Manual, verzija 2.2, 1995).

Pored te dve metode za transformaciju geodetskih datuma, kao moguću trebalo bi pomenuti i metodu jednačina višestruke regresije. Njena osnovna prednost je u modelovanju nešto boljeg uklapanja kontinualnih površi u odnosu na metodu Molodenskog, ali zahteva i određivanje mnogo većeg broja konstanti, što nije tako praktično i jednostavno (WGS84 - Implementation Manual, verzija 2.2, 1995).

\section{Kartografska osnova}

Kartografska projekcija određuje prelaz od površi elipsoida na ravan, dajući istovremeno zakon rasporeda pri nastalim deformacijama. Ona izražava analitičku zavisnost između koordinatnih tačaka na Zemljinom elipsoidu i ravni, i time predodređuje obavezan redosled radova u računanju i konstrukciji kartografske osnove topografske karte, izražene odgovarajućim sistemom koordinatnih linija. Takva koordinatna mreža je obavezna osnova svake, a posebno topografske karte.

Sadašnje topografske karte, kao što je poznato, rađene su u Gaus-Krigerovoj projekciji trostepenih zona, na Zemljinom elipsoidu Besela 1841, sa griničkim početnim meridijanom. Meridijani koji- ma odgovara $18^{\circ}$ i $21^{\circ}$ istočne geografske dužine srednji su meridijani zona, a linearni modul (razmera) na srednjem meridijanu zone iznosi 0,9999. U budućoj upotrebi i izradi topografskih karata, predlaže se UTM projekcija. Ona spada u kategoriju konformnih kartografskih projekcija, što znači da omogućava očuvanje sličnosti figura (jednakost uglova). Takav način preslikavanja ima veliku primenu u mnogim oblastima ljudske delatnosti, a jedna od tih oblasti jeste i vojska.

Pravougli koordinatni sistemi UTM pokrivaju Zemljinu površ između $80^{\circ}$ južne geografske širine i $84^{\circ}$ severne geografske širine. Svaka meridijanska zona ima svoj samostalni sistem pravouglih koordinata u ravni sa početkom u preseku ekvatora sa srednjim meridijanom te zone. Koordinate rastu u smeru istoka i severa (slika 3). Horizontalna koordinatna osa označava se slovom E, a uspravna koordinatna osa slovom N. Radi izbegavanja pojavljivanja negativnih vrednosti koordinata E dodaje im se konstanta od $500000 \mathrm{~m}$, tako da svaki centralni meridijan ima vrednosti $500000 \mathrm{~m}$. Za tačke koje se nalaze južno od ekvatora još se koordinati $\mathrm{N}$ dodaje konstanta od $10000000 \mathrm{~m}$. Na taj način će svaki koordinatni sistem imati početak za severnu hemisferu (u metrima) $50000 \mathrm{E}, 0 \mathrm{~N}$, a za južnu 500000 E i 10000000 N.

Kada je reč o sistemu vojnih kartografskih izdanja jasno je da on mora rešavati kompleks zadataka taktičkog, operativnog i strategijskog karaktera. Pri izradi novog topografsko-kartografskog sistema predlaže se izrada topografskih karata u sledećim razmerama: 1:50 000 (level 2), 1:250 000 (level 1) i 1:1000 000 (level 0). Navedene razmere rezultat su 


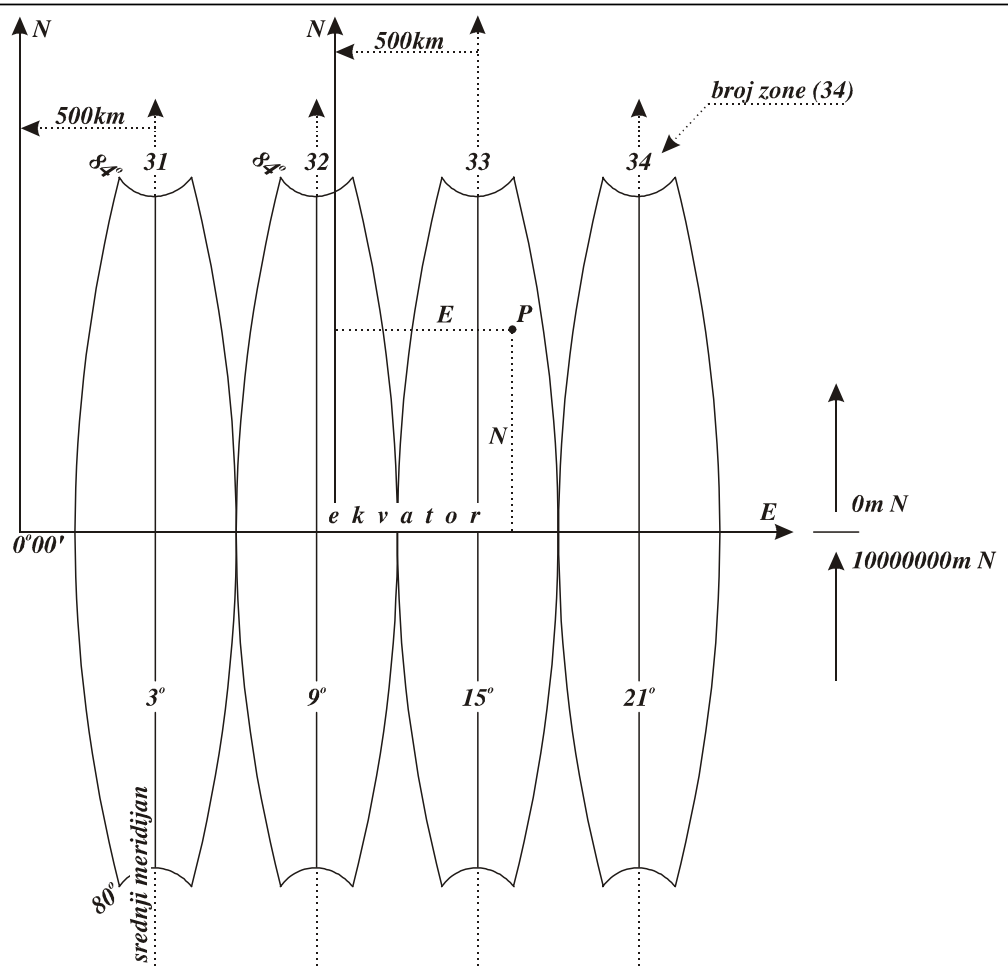

Sl. 3 - Prikaz meridijanskih zona i definicija koordinatnih sistema

vojnih standarda i međusobnih sporazuma zemalja članica NATO i zemalja članica Partnerstva za mir. Takođe, postoji podela teritorije kartiranja na određeni format listova. U tom smislu topografske karte treba osloniti na podelu i UTM sistem obeležavanja (slika 4). Četvorougao UTM pokrivaju dva lista karte u razmeri 1:1 000000 . Odlike te osnove za prikaz područja državne teritorije SCG i delova susednih država su:

- četvorougao UTM je 34T;

- širina zone iznosi $6^{\circ}$ po geografskoj dužini, gde je $21^{\circ}$ srednji meridijan zone ( 34 je broj zone) i $8^{\circ}$ po geografskoj širini (red je T);

- apscisna osa je ekvator, a ordinatna osa srednji meridijan zone;
- linearna razmera na srednjem meridijanu iznosi 0,9996 (najveća deformacija preslikavanja je na sredini zone, a najmanja na krajevima, tj. na krajevima zone nema deformacija),

- konvergencija meridijana mora biti manja od $5^{\circ}$.

Podelom jednog lista međunarodne karte sveta za razmeru 1:1000000 na tri kolone i četiri reda nastaje 12 listova u razmeri 1:250000 (slika 5). Pojedini listovi označavaju se brojevima od 1 do 12, po redovima, počevši od severozapadnog vrha u smeru istoka i juga. Označavanje listova karata 1:250000 dopunjava se nazivom najznačajnijeg grada prikazanog na listu i nazivima država prikazanih na listu. Daljom podelom lista karte $u$ razmeri 1:250 000 na pet redova $i$ 

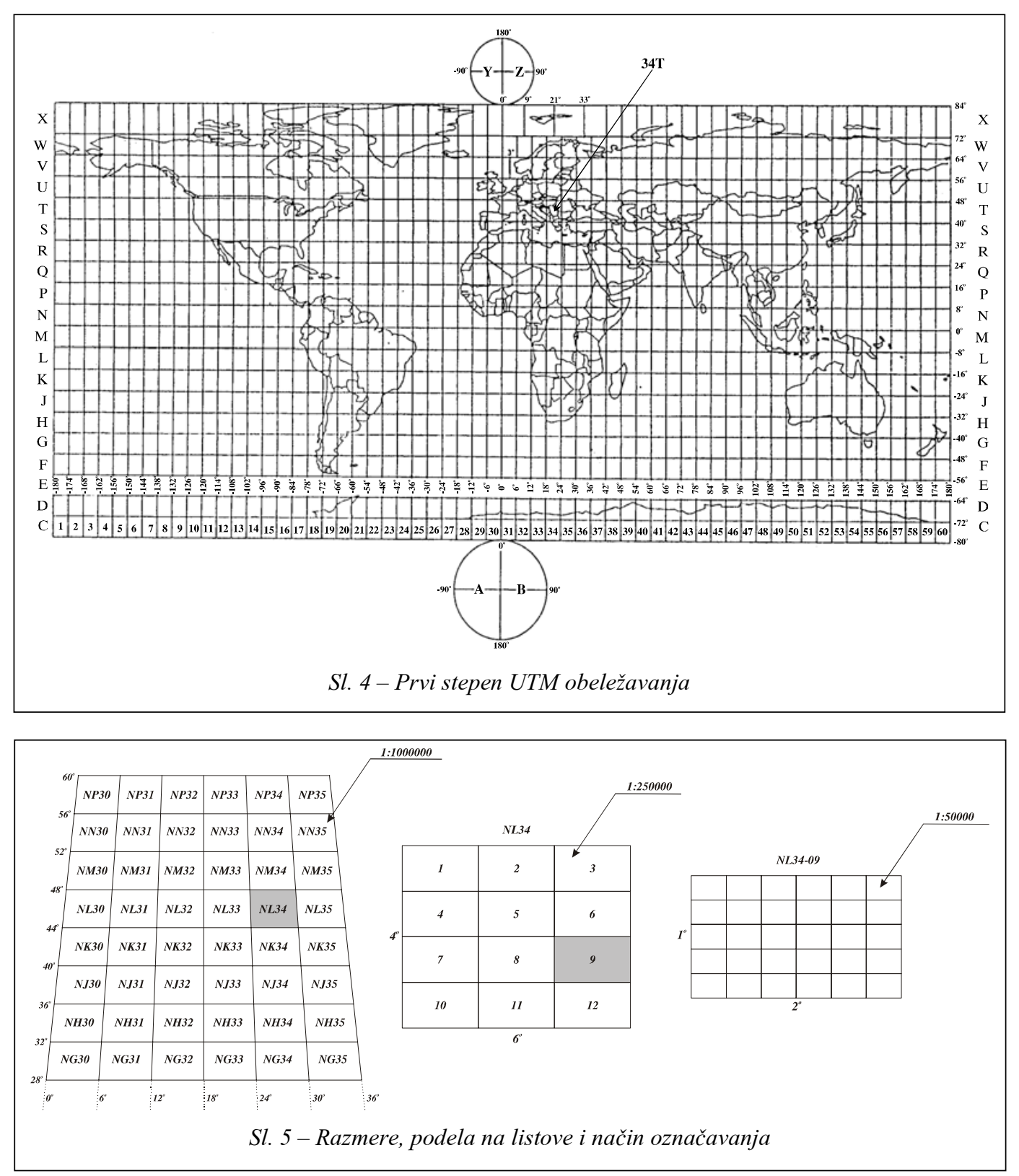

šest kolona nastaje 30 listova u razmeri 1:50 000. Format listova u razmeri 1:50 000 iznosi 20' po geografskoj dužini i 12 ' po geografskoj širini.

Radi jednoznačnosti identifikacije tačaka bilo gde na Zemlji prihvaćena je takozvana vojna pravougla mreža UTM.
Počevši od ekvatora u smeru severa i juga i od srednjeg meridijana na zapad i istok definisan je sistem kvadrata $100 \times 100 \mathrm{~km}$, čije su stranice u ravni projekcije paralelne sa projekcijom ekvatora i srednjeg meridijana pripadajuće zone. Sa sužavanjem meridijanskih zona $\mathrm{u}$ smeru polova zona 
sadrži određeni broj potpunih kvadrata (na našoj geografskoj širini samo 4), a ivični „kvadrati“ su nepotpuni. Na slici 6 dat je prikaz dela UTM zone koja obuhvata državnu teritoriju SCG. Našu teritoriju pokriva zona 34 , koja se prostire između meridijana $18^{\circ}$ i $24^{\circ}$ istočne geografske dužine, sa meridijanom $21^{\circ}$ istočne geografske dužine, kao centralnim. Takođe, prikazani su podela i način označavanja kvadrata $100 \times 100 \mathrm{~km}$ za područje SCG.

Početak obeležavanja kvadrata poklapa se sa koordinatnim početkom svake UTM zone. Počevši od $180^{\circ}$ geografske dužine, idući istočno duž ekvatora $\mathrm{u}$ intervalima po $18^{\circ}$, kolone kvadrata obeležene su slovima abecede od $\mathrm{A}$ do $\mathrm{Z}$ (slova I i O su izostavljena). Redovi se obeležavaju od juga prema severu, slovima A do Y (slova I i O su izostavljena). Abeceda se ponavlja svakih $200 \mathrm{~km}$. U parno obeleženim zonama redovi počinju da se obeležavaju abecednim redom, počevši od apscisne linije sa vrednošću od $500000 \mathrm{~m}$ i to od juga prema severu.

Način određivanja koordinata tačaka u vojnoj pravougloj UTM mreži takode je normiran. Na primer, postupak određivanja položaja izabrane tačke podrazumeva (slika 7):

- određivanje UTM četvorougla;

- određivanje oznake pripadajućeg kvadrata $100 \times 100 \mathrm{~km}$;

- određivanje punog kilometra istočno od zapadne ivice pripadajućeg kvadrata $100 \times 100 \mathrm{~km}$;

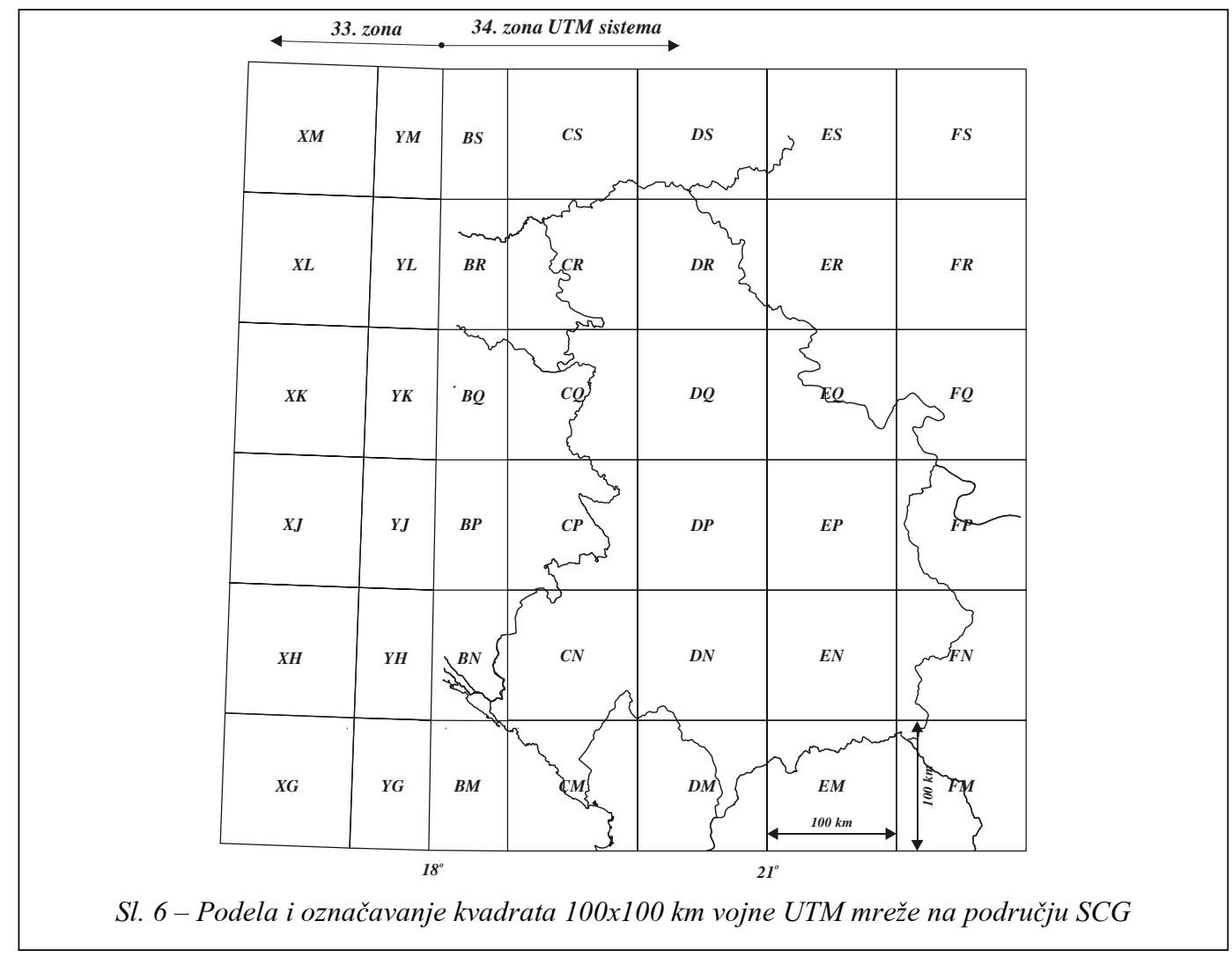



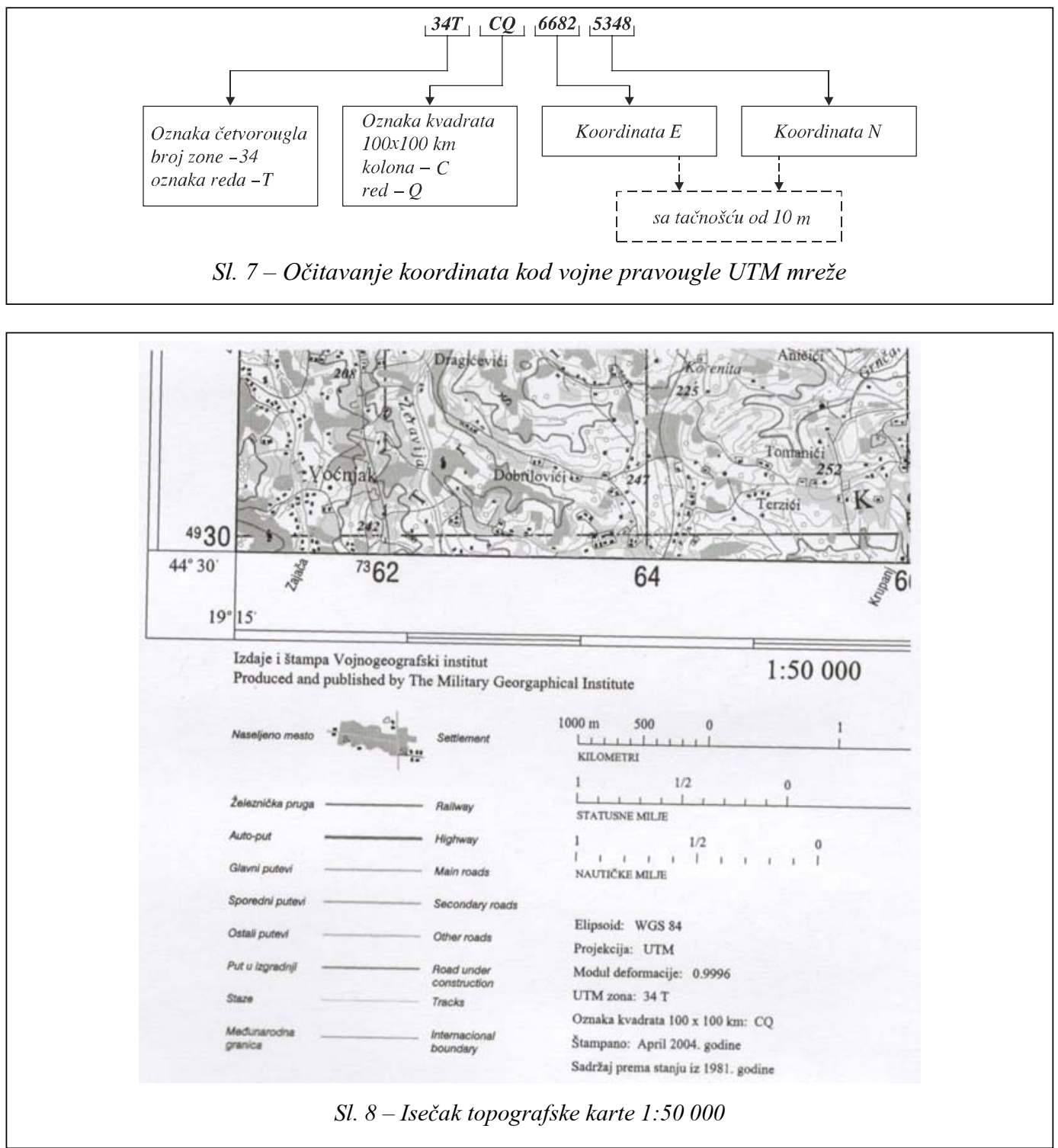

- procenu udaljenosti objekta od određenog punog kilometra sa tačnošću od $10 \mathrm{~m}$;

- određivanje punog kilometra severno od južne ivice pripadajućeg kvadrata $100 \times 100 \mathrm{~km}$,

- procena udaljenosti objekta od određenog punog kilometra sa tačnošću od $10 \mathrm{~m}$.
Vanokvirni sadržaj na novim topografskim kartama ima mnogo više sadržaja nego što je to bilo do sada. Proširuje se novim informacijama, kao i uputstvima za lakše snalaženje i očitavanje podataka. Takođe, tekst u vanokvirnom sadržaju, osim na srpskom (nacionalnom) jeziku, daje se i na engleskom (slika 8). 


\section{Transformacija kartografskog sadržaja}

Sa potrebom izgradnje topografsko-kartografskog sistema prema novim vojnim standardima, postoji mogućnost prilagođavanja sadašnjih geotopografskih materijala $\mathrm{u}$ okviru međunarodnog referentnog koordinatnog sistema. Matematički postupak kojim se određuje jednoznačna veza između starog i novog sistema predstavlja transformaciju kartografskog sadržaja i, u principu, postoje dva rešenja za dati problem: direktni i indirektni način.

U mnogim slučajevima određivanje direktne analitičke veze, odnosno definisanje odgovarajućih funkcija transformacije praktično je teško ostvarljivo. Zbog toga se najčešće pribegava približnim rešenjima, odnosno iznalaženjima približnih formula koje obezbeđuju dovoljnu tačnost za mnoge praktične potrebe. Opšte rešenje navedenog problema zasniva se na modelovanju funkcionalne veze između koordinata dva referentna sistema stepenovanim polinomom oblika:

$$
\begin{aligned}
& X=a_{0}+\sum_{i=1}^{\infty}\left(a_{i n} x+a_{i m} y\right)^{i} \\
& Y=b_{0}+\sum_{i=1}^{\infty}\left(b_{i n} x+b_{\text {im }} y\right)^{i}
\end{aligned}
$$

gde je:

$a_{0}, b_{0}, a_{i}, b_{i}$ - koeficijenti transformacije, $i$ - stepen transformacije,

$n, m$ - redni brojevi, koji u svakom redu transformacije poprimaju značenje od $n=1$ do $m=i+1$.
Najverovatnije vrednosti koeficijenata $a_{0}, b_{0}, a_{i}$ i $b_{i}$ određuju se primenom principa najmanjih kvadrata $\sum\left(v_{x}^{2}+v_{y}^{2}\right)=\min$, gde su $v_{x}$ i $v_{y}$ popravke koordinata. Specijalan slučaj polinoma (1) su jednačine afine transformacije koje nastaju ako se ostane na članovima do prvog stepena, i mogu se izraziti na sledeći način:

$$
\begin{aligned}
& X=a_{0}+a_{11} x+a_{12} y \\
& Y=b_{0}+b_{11} x+b_{12} y
\end{aligned}
$$

Afina transformacija ima veliku primenu pri preslikavanju srodnih kartografskih mreža kada je poželjno sačuvati osobinu paralelnosti pravaca. Međutim, često postoji potreba za transformacijom viših stepena, kada je neophodno preslikavanje pravih u krive linije. Takva je, na primer, transformacija drugog stepena zadata sledećim izrazima:

$$
\begin{aligned}
& X=a_{0}+a_{11} x+a_{12} y+a_{21} x^{2}+a_{22} x y+a_{23} y^{2} \\
& Y=b_{0}+b_{11} x+b_{12} y+b_{21} x^{2}+b_{22} x y+b_{23} y^{2}
\end{aligned}
$$

Ove jednačine predstavljaju krive linije drugog stepena (parabole, hiperbole, elipse i sl.). Takav vid transformacije određen je sa šest zajedničkih tačaka, dok transformaciju trećeg i višeg stepena određuje više zajedničkih tačaka.

Indirektno rešenje vodi preko niza pravouglih i geografskih koordinata odgovarajućih tačaka, i može se šematski prikazati kao: 


$$
\begin{aligned}
& {[x, y]_{1} \rightarrow[\varphi, \lambda]_{1} \rightarrow[X, Y]_{1} \rightarrow} \\
& \rightarrow[X, Y]_{2} \rightarrow[\varphi, \lambda]_{2} \rightarrow[x, y]_{1}
\end{aligned}
$$

gde su:

$x, y$ - pravougle koordinate u ravni, $\varphi, \lambda$ - geografske koordinate,

$X, Y$ - prostorne pravougle koordinate,

1 - stari sistem,

2 - novi sistem.

Postupak indirektne transformacije je u svemu striktno definisan, i za njegovu realizaciju neophodno je raspolagati preciznim formulama za prelaz iz ravni kartografske projekcije na određeni elipsoid i obratno. Za sada postoji veliki broj programa i algoritama koji rešavaju upravo ovu problematiku. Radi transformacije postojećeg kartografskog sadržaja u novi jedinstveni standardni koordinatni sistem, na slici 9 prikazano je indirektno rešenje.

Do izrade potpuno novog topografsko-kartografskog sistema postoji mogućnost nanošenja, tj. da se na sadašnje vojne topografske karte ucrta kartografska mreža UTM projekcije, ali prema podacima WGS84. Ovakva mreža već se uštampava na određenom broju postojećih karata, kao što su, na primer, topografska karta u razmeri 1:50000 i topografska karta u razmeri 1:100 000. Takođe, u vanokvirnom sadržaju ovih karata daje se odgovarajuće objašnjenje za njihovu upotrebu, odnosno očitavanje koordinata položaja u jednom ili drugom koordinatnom sistemu.

\section{Zaključak}

U nedavnoj prošlosti svaka država se zadovoljavala uspostavljanjem jednorod- nog sistema u okviru svojih nacionalnih (lokalnih) granica. Taj sistem je, prema potrebama i mogućnostima, proširivan na teritorije susednih zamalja. I naša zemlja imala je svoje osnovne podatke o referenc-elipsoidu, fundamentalnoj tački, kartografskoj projekciji ili sistemu razmera topografskih karata. Usled globalnih svetskih kretanja i međunarodne vojne saradnje, geodetsko-kartografski sistemi postali su tesni i predstavljaju smetnju ubrzanoj integraciji većeg broja zemalja, kako na vojnom, tako i na civilnom planu.

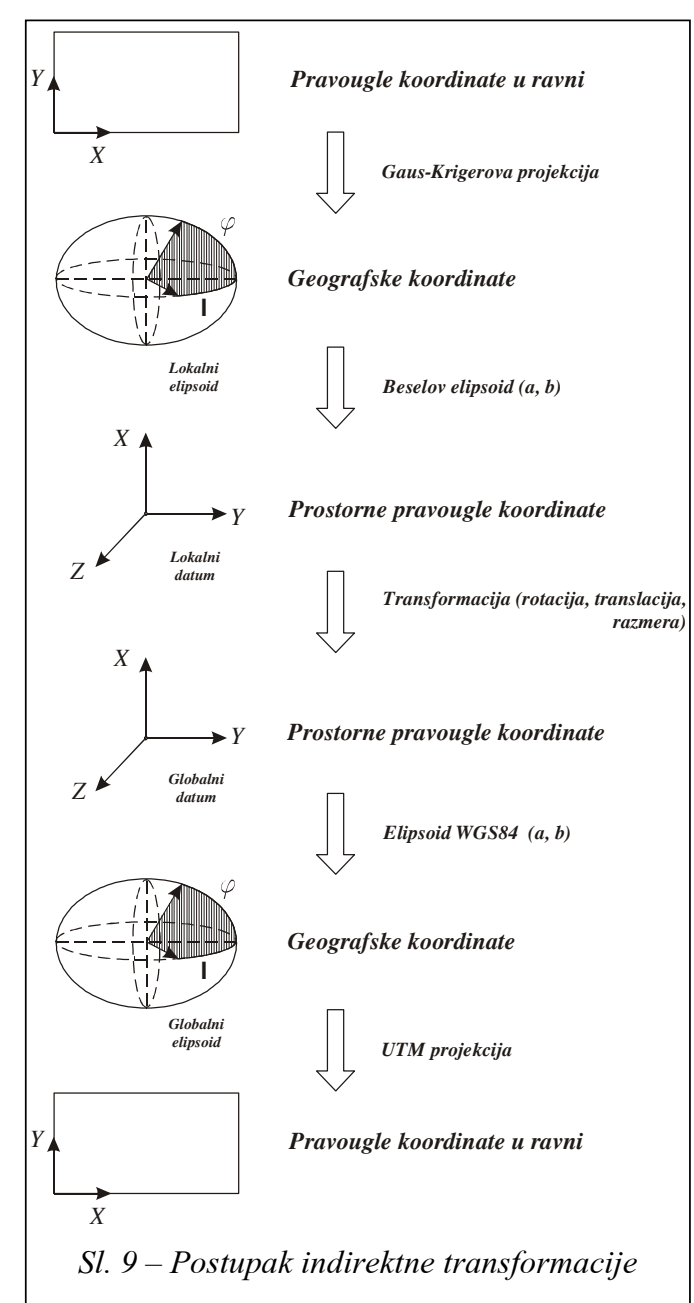


Poslovi na obnovi matematičke osnove topografskih karata kod nas danas su postali neophodni, kao što je neophodna i ažurnost geoprostornog sadržaja. Za to treba stvoriti što povoljnije uslove, jer je to posao koji zahteva ozbiljnu teorijsku pripremu i poznavanje svetskih iskustava u datoj oblasti. Takođe, potrebni su stručni kadrovi, mnogo smišljenog i kreativnog rada, a i puno vremena. Takav zadatak obično nastaje u prelomnim trenucima ili kada je obezbeđena jedna serija vojnih topografskih karata, pa se posao može preusmeriti na nove projekte. Međutim, u ovom slučaju ne bi trebalo puno odugovlačiti, s obzirom na naša velika zaostajanja na tom polju, kao i potrebe za što bržim priključenjem savremenom delu sveta. U formiranje jednog takvog sistema, osim vojne geodetske službe, u velikoj meri mogu se uključiti i drugi geodetsko-kartografski potencijali na polju prikupljanja i izgradnje okvira podataka o prostoru.

Literatura:

[1] Borisov, M., (2004): Model i organizacija geoprostornih podataka za razmeru 1:50 000, Doktorska disertacija, Građevinski fakultet-Institut za geodeziju, Beograd.

[2] DMA, (2000): The Digital Geographic Information Exchange Standard (DIGEST), USA.

[3] Illert, A.; Wilski, I., (1995): Integration and harmonization of contributions to a European dataset, $17^{\text {th }}$ International Cartographic Conference $10^{\text {th }}$ General Assembly of ICA Proccedings 1, Barselona, Espania, pp. 805-813.

[4] STANAG 2211, (2000): Geodetic Datums, Projections, Grids and Grid References, North Atlantic Treaty Organization, Military Agency for Standardization, Edition 6.

[5] STANAG 3600, (2000): Topographical Land Maps and Aeronautical Charts 1:250 000 for Joint Operations, North Atlantic Treaty Organization, Military Agency for Standardization, Edition 3/1979, Amendment 9/2000.

[6] Une Hiroshi, (2001): Toward the Next Stage of the Global Mapping Project - Successful Completion of Phase 1 with Release of Global Map Version 1.0, Bulletin of the Geographical Survey Institute, Vol. 47, Japan, pp. 13-21.

[7] http://www.nc3a.nato.int/symposia/accisamis/proceedings/s2gismil/giscrono.htm

[8] http://www.cartographic.com/topograp-hicmaps.asp

[9] WGS 84, (1995): Implementation Manual, Verzija 2.2, European Organization for the Safety of Air Navigation Brussels, Belgium, and Institute of Geodesy and Navigation University FAF Munich, Germany. 


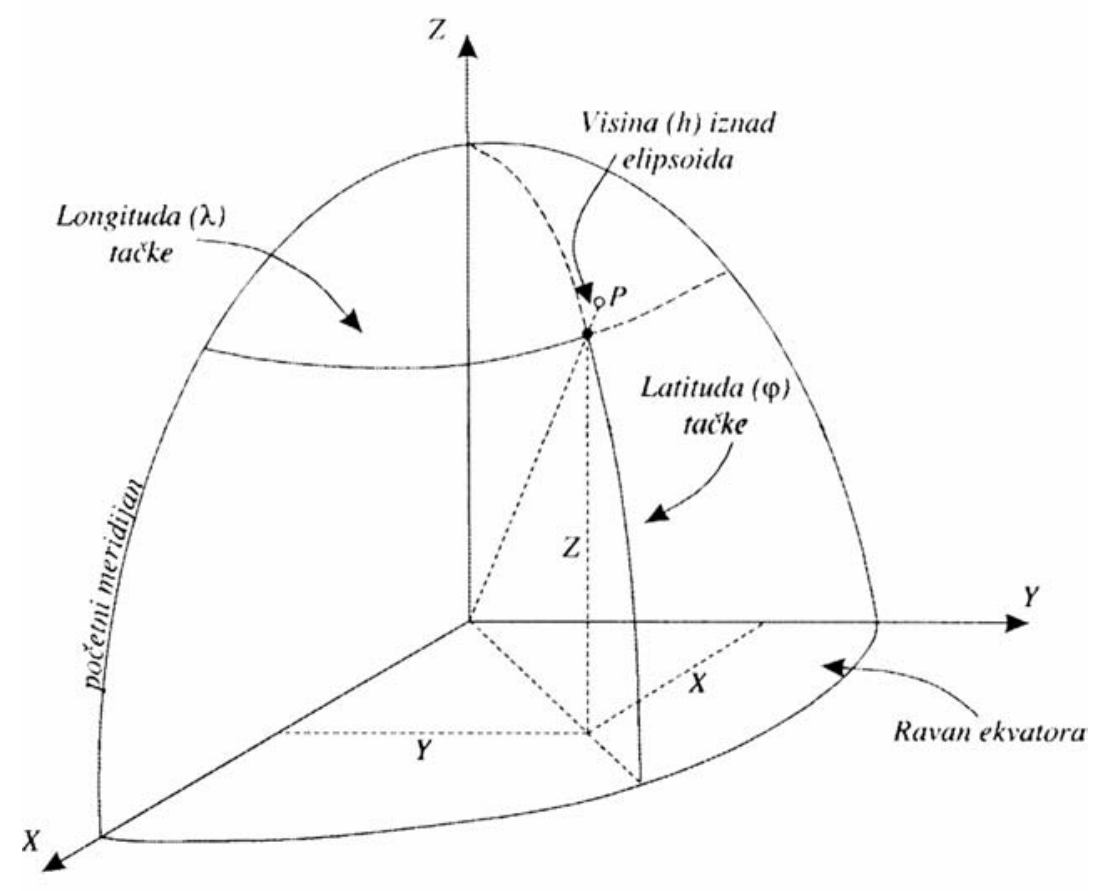

Sl. 1 - Pravolinijski i krivolinijski koordinatni sistem

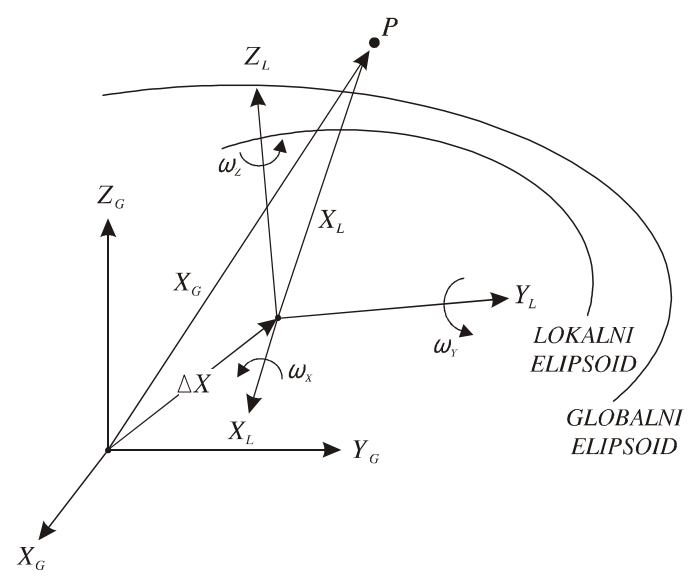

Sl. 2 - Transformacija geodetskog datuma:

$X_{G}$ - položaj tačke P u globalnom sistemu, $X_{L}-$ položaj tačke u lokalnom sistemu,

$\Delta X$ - parametar translacije, $\omega_{x}, \omega_{y}, \omega_{z}-$ uglovi rotacije,

$$
\mu \text { - faktor razmere. }
$$




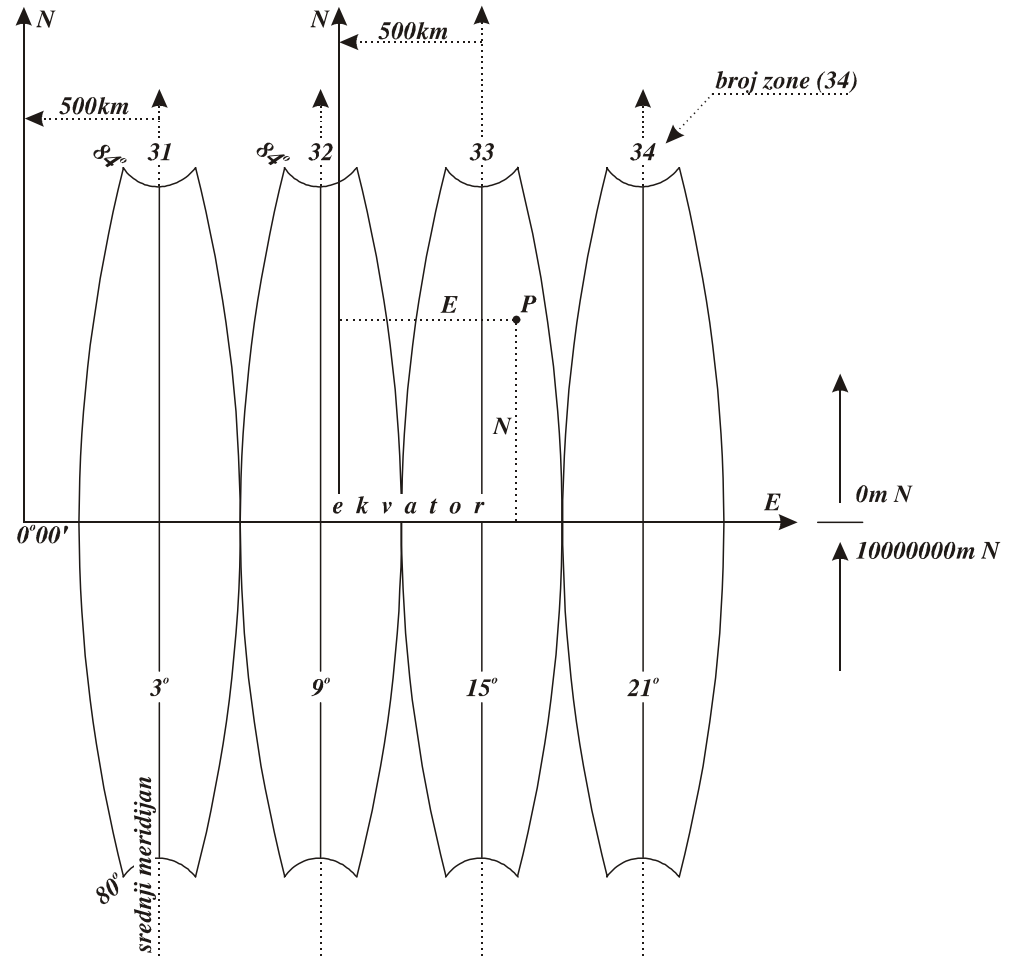

Sl. 3 - Prikaz meridijanskih zona i definicija koordinatnih sistema 

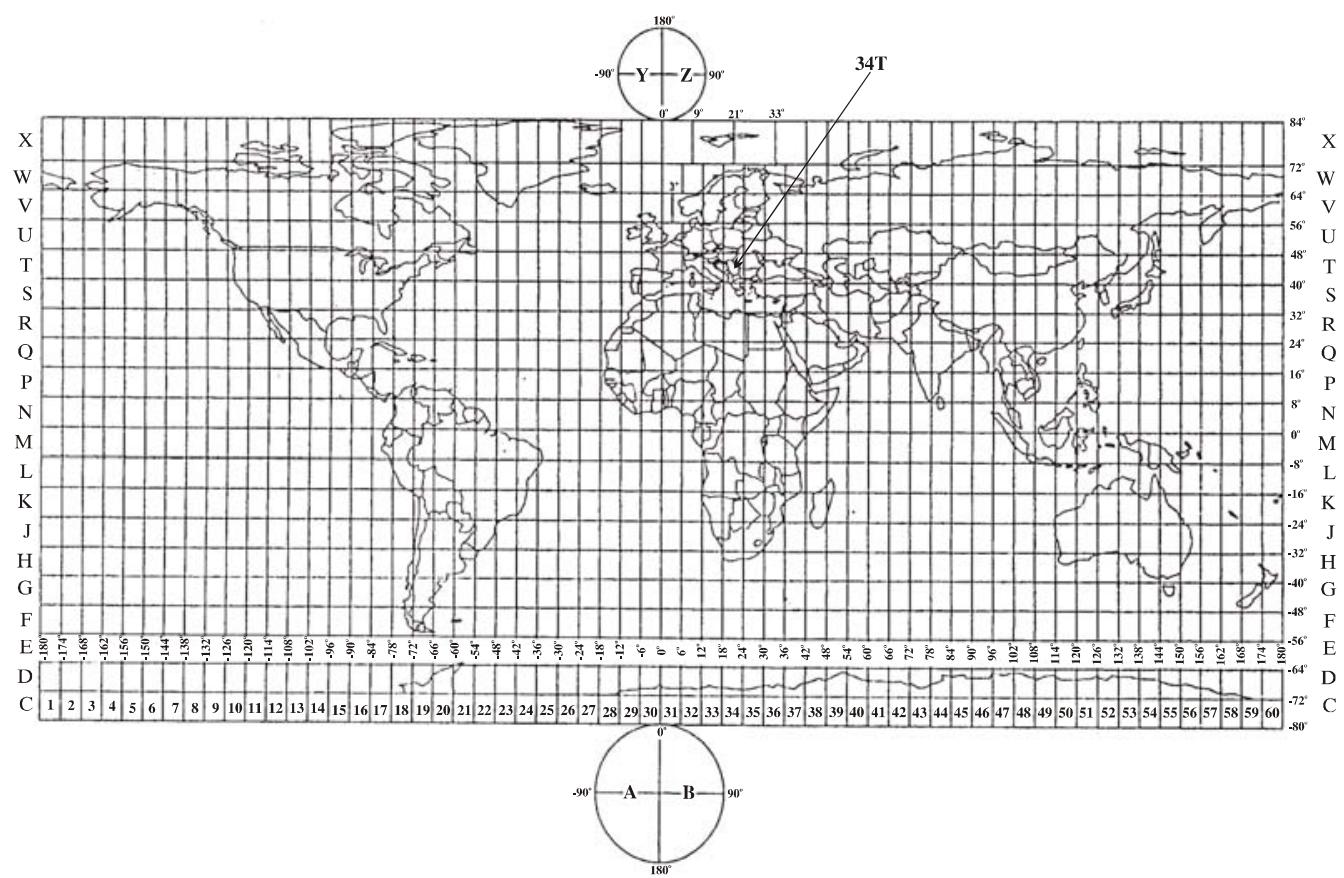

Sl. 4 - Prvi stepen UTM obeležavanja

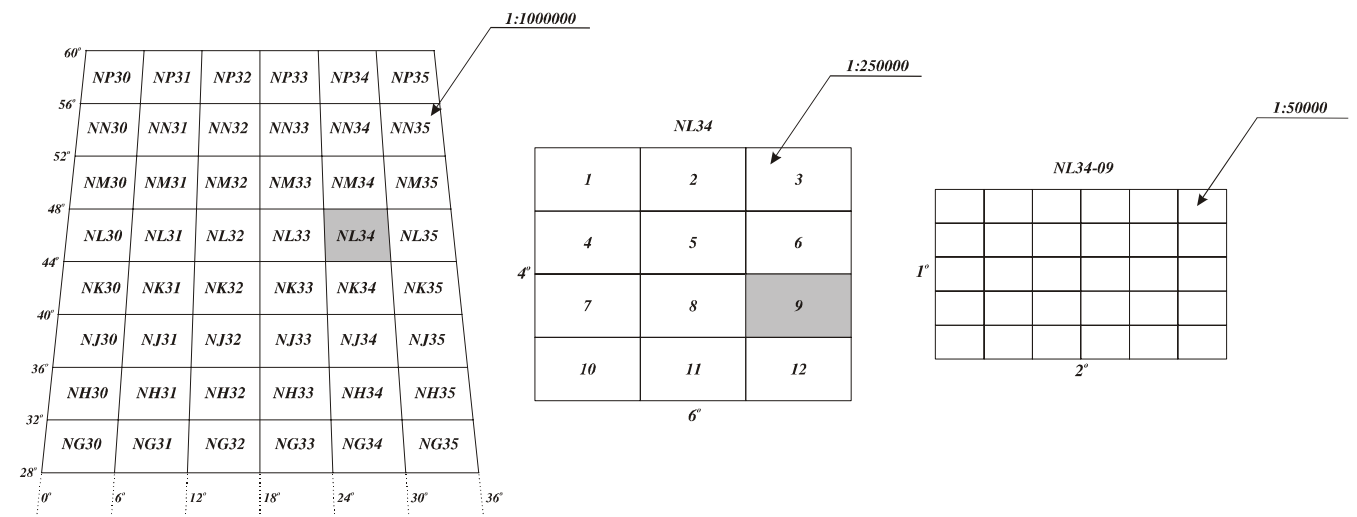

Sl. 5 - Razmere, podela na listove i način označavanja 


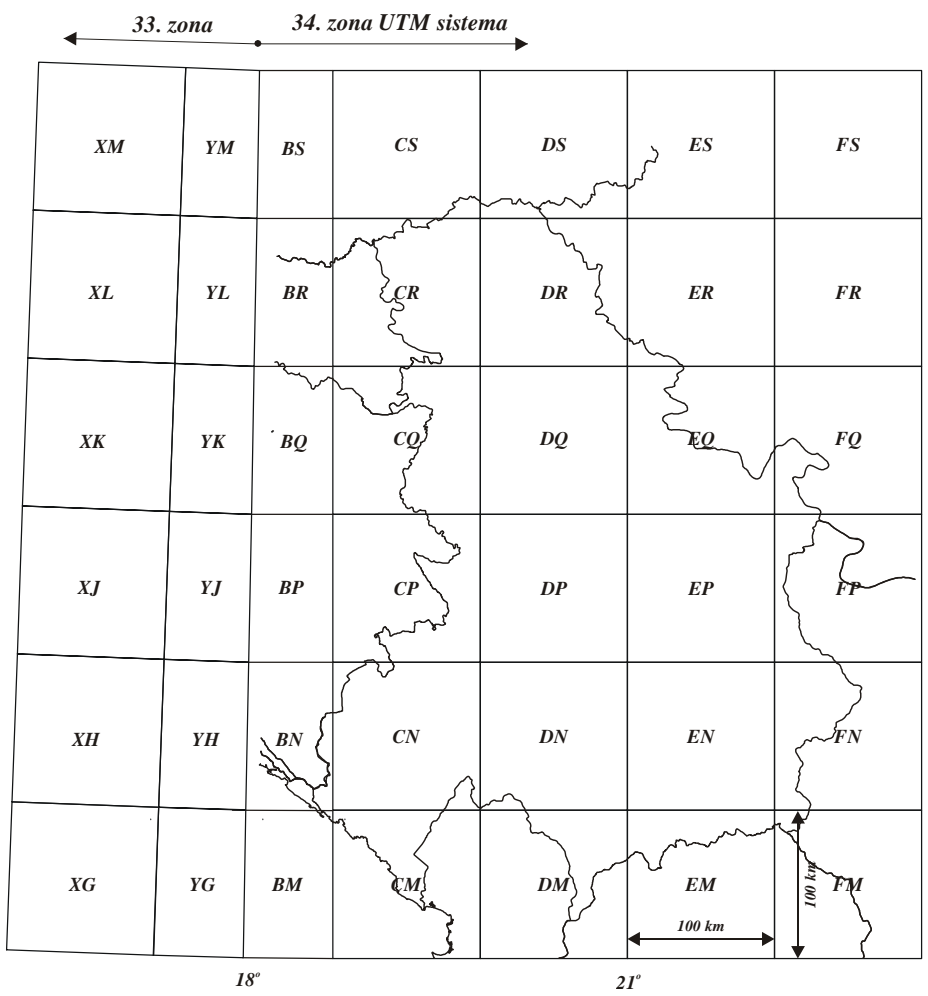

Sl. 6 - Podela i označavanje kvadrata $100 \times 100$ km vojne UTM mreže na području SCG

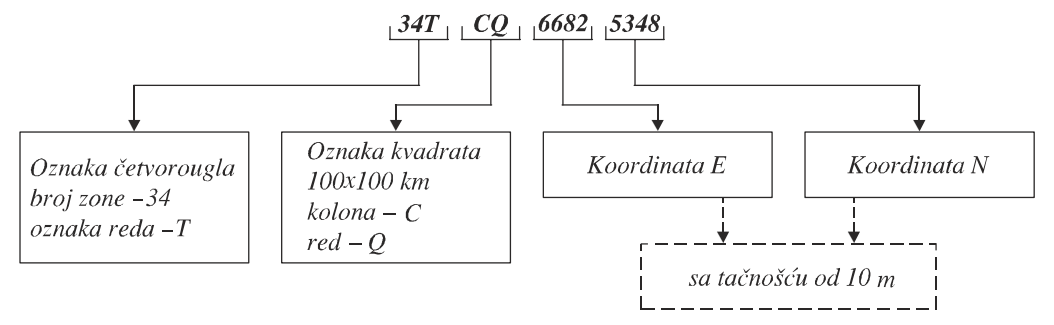

Sl. 7 - Očitavanje koordinata kod vojne pravougle UTM mreže 


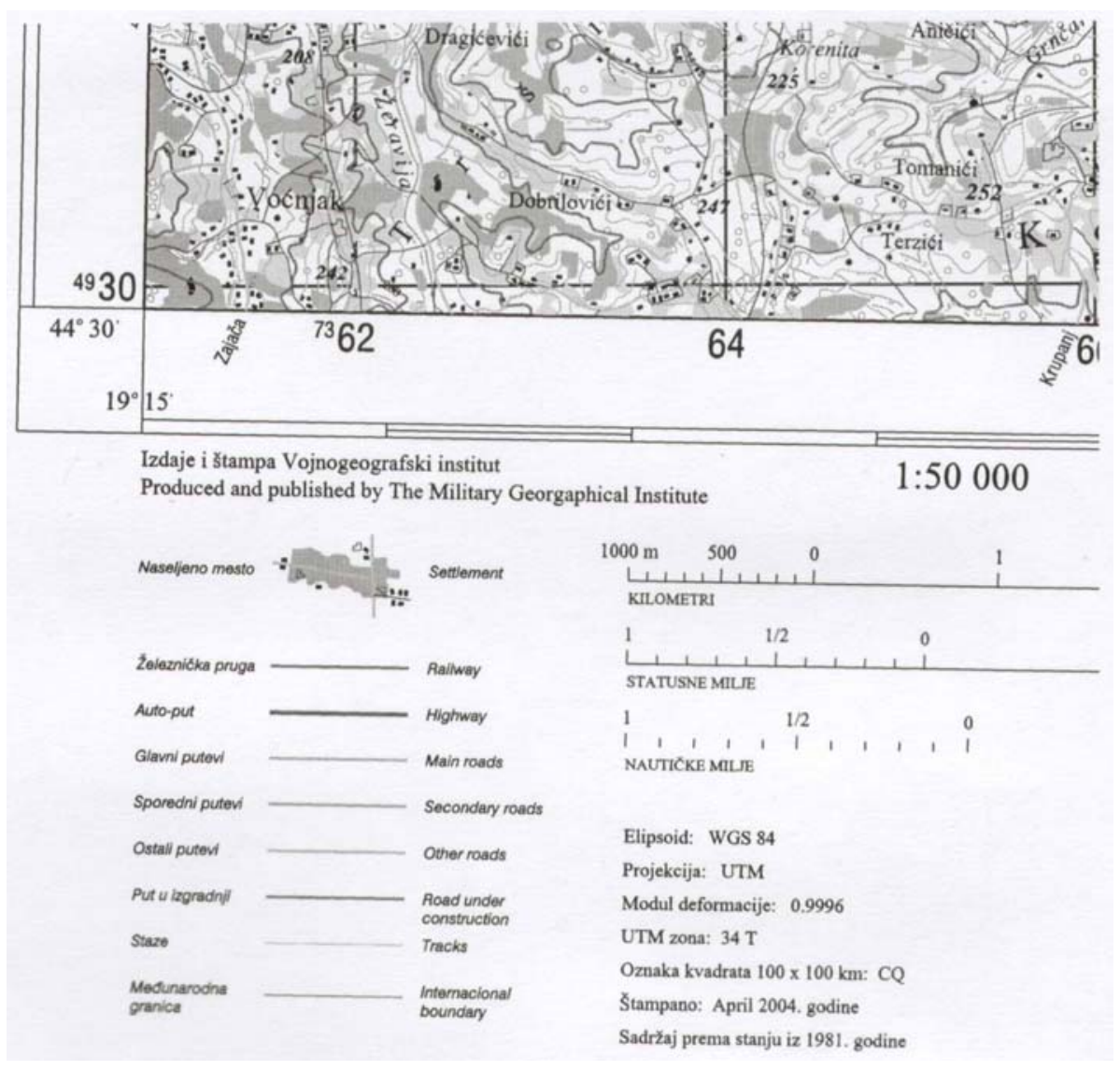

Sl. 8-Isečak topografske karte 1:50 000 


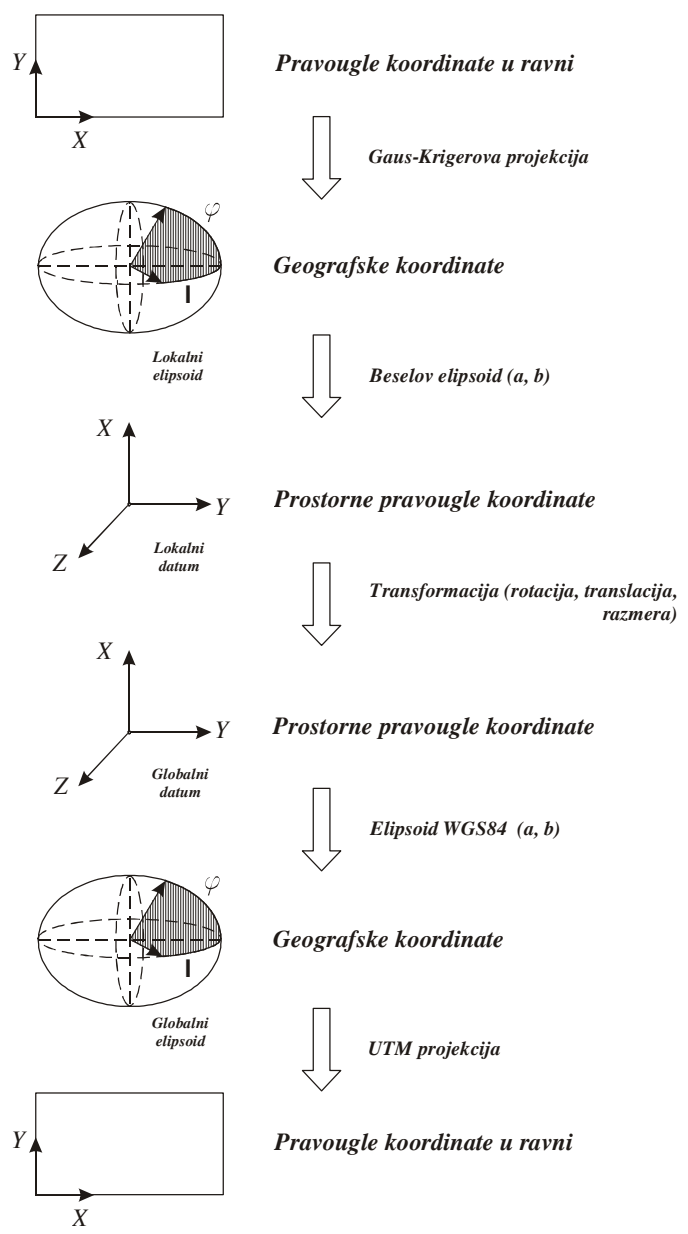

Sl. 9 - Postupak indirektne transformacije 
